\title{
Influence of pH, Precursor Concentration, Growth Time, and Temperature on the Morphology of ZnO Nanostructures Grown by the Hydrothermal Method
}

\author{
G. Amin, M. H. Asif, A. Zainelabdin, S. Zaman, O. Nur, and M. Willander \\ Department of Science and Technology, Linköping University, Norrköping Campus, 60174 Norrköping, Sweden \\ Correspondence should be addressed to G. Amin, gulam@itn.liu.se
}

Received 7 June 2011; Revised 27 July 2011; Accepted 29 July 2011

Academic Editor: Yanqiu Zhu

Copyright $\odot 2011$ G. Amin et al. This is an open access article distributed under the Creative Commons Attribution License, which permits unrestricted use, distribution, and reproduction in any medium, provided the original work is properly cited.

\begin{abstract}
We investigated the influence of the $\mathrm{pH}$ value, precursor concentration $(C)$, growth time and temperature on the morphology of zinc oxide $(\mathrm{ZnO})$ nanostructures. The $\mathrm{pH}$ of the starting solution was varied from 1.8 to 12.5 . It was found that the final $\mathrm{pH}$ reaches an inherent value of 6.6 independently of the initial $\mathrm{pH}$ solution. Various $\mathrm{ZnO}$ structures of nanotetrapod-like, flower-like, and urchin-like morphology were obtained at alkaline $\mathrm{pH}$ ( 8 to 12.5 ) whereas for $\mathrm{pH}$ solution lower than 8 rod-like nanostructures occurred. Moreover, we observed the erosion of the nanorods for a $\mathrm{pH}$ value less than 4.6. By changing the concentrations the density and size were also varied. On going from a high $(C>400 \mathrm{mM})$ to lower $(C<25 \mathrm{mM}) C$, the resulted ZnO nanostructures change from a film to nanorods (NRs) and finally nanowires (NWs). It was also found that the length and diameter of ZnO NRs follow a linear relation with time up to 10 hours, above which no further increase was observed. Finally the effect of growth temperature was seen as an influence on the aspect ratio.
\end{abstract}

\section{Introduction}

Zinc oxide $(\mathrm{ZnO})$ is a promising material with wide bandgap of $3.4 \mathrm{eV}$ and relatively large exciton binding energy of $60 \mathrm{meV}$ [1]. Zinc oxide is also characterized by having excellent chemical stability, nontoxicity, and good electrical, optical, and piezoelectric properties $[1,2]$. This material also possesses a rich family of nanostructures (NSs). It has been predicted that in general NSs will play an important role in the future in a variety of practical applications, including optoelectronic devices, for example, solar cells [3], UV sensors [4], biosensors [5], and light emitting diodes [6$8]$. For these applications, it is essential to have a thorough understanding of the growth mechanism to achieve the desired morphology of the $\mathrm{ZnO}$ NSs needed. Since the properties of $\mathrm{ZnO}$ NSs strongly depend on its morphology and shape, it is also essential to precisely control their size, shape, and surface architecture to utilize its properties in different practical fields. However, many methods have been applied to the synthesis of $\mathrm{ZnO}$ NSs, such as metal organic chemical vapor deposition (MOCVD) [9], electrochemical deposition techniques [10], sputter deposition techniques [11], and pulse laser deposition method [12]. But those methods require severe reaction conditions, such as high temperature, accurate gas concentration, and flow rate or complex processes. So it is important to find a simple, lowtemperature method for the synthesis of $\mathrm{ZnO}$ NSs and find a way to control the growth parameters. Compared with the above synthesis processes, the $\mathrm{ZnO}$ NSs were grown by using the hydrothermal method. This growth method showed some advantages compared with others such as the use of simple setup, relatively low temperature, large area deposition, and low cost and is environment friendly. There are several parameters in the hydrothermal method that can affect the growth of the $\mathrm{ZnO}$ NSs such as seeding of the substrate which increases the density and alignment of the NSs [13], thickness of the seed layer which can be controlled simply by the speed of spin coating, and also presence of impurities in the seed layer which can strongly influence the growth and crystallinity of the ZnO NSs [14]. Other parameters like angle of the inclination, for example, whether the substrate is placed vertically or inclined with the walls of 
heating bath, temperature, time, concentration, and $\mathrm{pH}$ have also an influence. Using different precursors from the one used here, the temperature was found to affect the synthesis of $\mathrm{ZnO}$ nanorods, for example, the length and diameter of the NRs increased with increasing the temperature [15]. It has been reported that the time is largely influencing the $\mathrm{ZnO}$ NRs diameter; longer synthesis time leads to larger diameter NRs [16]. The dimension of $\mathrm{ZnO}$ NRs was also found to be affected by the zinc ions concentration [16]. The role of the $\mathrm{pH}$ on the hydrothermal growth of the $\mathrm{ZnO}$ NRs was examined, and it was shown that the effect of the $\mathrm{pH}$ is crucial because hydroxide ions $\left(\mathrm{OH}^{-}\right)$are strongly related to the reactions that produce the ZnO NSs [17-19]. Nevertheless, in the above-mentioned published results either only one parameter was considered or it was for a different precursor than the one used here. Furthermore, none of the published reports have been used to examine the growth of the $\mathrm{ZnO}$ NSs under a $\mathrm{pH}$ value $\ll 7$. Therefore, several fundamental reaction parameters need to be addressed to understand its influence on the growth.

In this paper, we present a study of the effect of different parameters on the morphology of ZnO NSs. These parameters are the solution $\mathrm{pH}$ (within a range of 1.812.5), temperature, time, and precursor concentration. We have conducted a systematic morphological and structural study of the grown samples. The results demonstrate that $\mathrm{ZnO}$ NSs morphological and structural characteristics can be controlled by adjusting the above-mentioned parameters.

\section{Experimental Procedure}

All the chemicals used in this study were of analytical reagent grade purchased from Sigma-Aldrich and used without further purification. The aqueous solutions containing the growth precursors were prepared using deionized water (DI) as a solvent. Silicon (100) substrates were chosen for the growth and were cleaned in ultrasonic bath using acetone, IPA (isopropyl alcohol), and DI water to remove dust and surface contamination. Then, they were etched by diluted hydrofluoric acid (HF) solution to get rid of the native oxide layer. For the ZnO NSs growth, a seed layer has been prepared using zinc acetate solution in ethanol as described in [20], and it was spin-coated on the substrates two times at a spin speed of $1000 \mathrm{rpm}$ for 30 seconds, followed by soft baking at $120^{\circ} \mathrm{C}$ for $5 \mathrm{~min}$. Figure 2(a) shows the atomic force microscope (AFM) image of seed layer coated substrate and its height profile which shows an average height of the particle $10-15 \mathrm{~nm}$. Seeding of the substrate with $\mathrm{ZnO}$ nanoparticles was found to lower the thermodynamic barrier by providing nucleation sites and thus it is an important parameter to achieve uniform growth of ZnO NSs through hydrothermal process [20]. The same procedure and conditions of depositing the seed layer are applied to all samples used in the experiments. The aqueous solution for the growth of $\mathrm{ZnO} \mathrm{NSs}$ was prepared using equimolar zinc nitrate hexahydrate $\left(\mathrm{Zn}\left(\mathrm{NO}_{3}\right)_{2} \cdot 6 \mathrm{H}_{2} \mathrm{O}, 99 \%\right)$ and hexamethylenetetramine (HMT) $\left(\mathrm{C}_{6} \mathrm{H}_{12} \mathrm{~N}_{4}, 99.5 \%\right)$. The solution was then transferred into different sealable glass beakers.

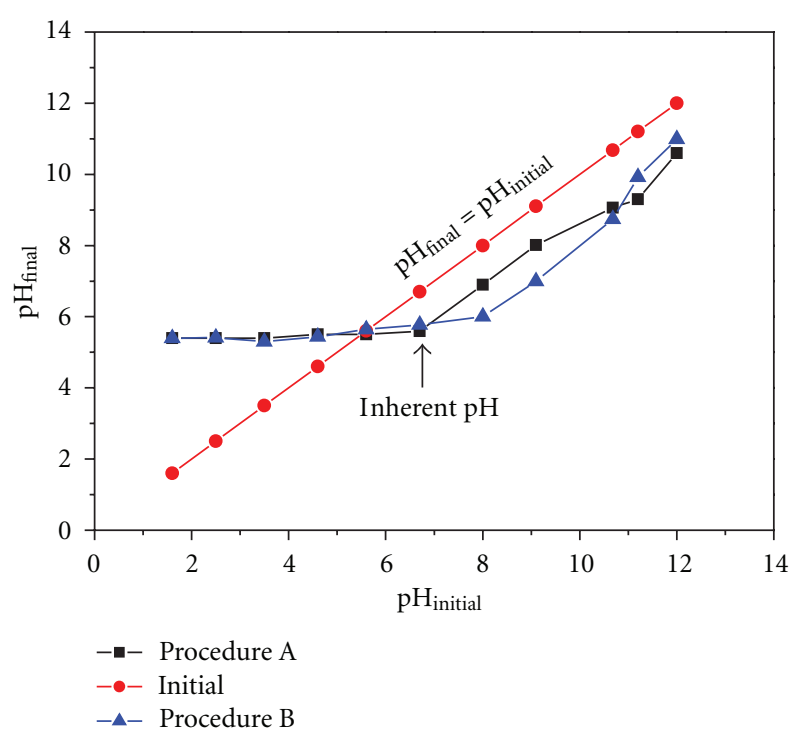

Figure 1: Plot of initial versus final $\mathrm{pH}$ of the precursor aqueous solution for the ZnO NSs in 5 hrs of growth time.

To investigate the role of the $\mathrm{pH}$ on the growth of the $\mathrm{ZnO} \mathrm{NSs}$, the solution was adjusted to different $\mathrm{pH}$ ranging from 1.8 to 12.5 , and in each beaker a preseeded substrate was suspended vertically for 5 hours (hrs) at $90^{\circ} \mathrm{C}$ in an ordinary oven. The $\mathrm{pH}$ values were varied by adding precise amounts of nitric acid $\left(\mathrm{HNO}_{3}\right)$ or ammonia $\left(\mathrm{NH}_{3} \cdot \mathrm{H}_{2} \mathrm{O}\right)$ (procedure A) and hydrochloric acid $(\mathrm{HCl})$ or sodium hydroxide $(\mathrm{NaOH})$ (procedure $\mathrm{B}$ ) to the aqueous solutions as $\mathrm{pH}$ controlling agents. The inherent $\mathrm{pH}$ of the solution was 6.6. At the end of the growth, the substrates were taken out of the solution and rinsed several times with deionized water then they were dried using high purity $\mathrm{N}_{2}$ gas at room temperature, and the $\mathrm{pH}$ of each solution was monitored after the growth ended. All the $\mathrm{pH}$ measurements were carried out with a $\mathrm{pH}$ meter from Metrohm Instruments.

To observe the effect of time and temperature, we used the same aqueous solution ( $100 \mathrm{mM}$ concentration) for the growth of $\mathrm{ZnO}$ NRs at different reaction times ( 1 to $20 \mathrm{hrs}$ ) at $90^{\circ} \mathrm{C}$ and different temperatures $\left(50^{\circ} \mathrm{C}\right.$ to $\left.110^{\circ} \mathrm{C}\right)$ for $5 \mathrm{hrs}$, respectively. To examine the influence of the concentration, an equimolar different precursor concentration solution $(5 \mathrm{mM}$ to $400 \mathrm{mM})$ was prepared for a growth time of $5 \mathrm{hrs}$ at a temperature $90^{\circ} \mathrm{C}$. The characterization of the NSs was performed using field emission scanning electron microscopy (SEM) and X-ray diffraction (XRD).

\section{Results and Discussion}

3.1. Influence of $p H$ on the Growth of $Z n O N S$. For the growth of materials with chemical route, the $\mathrm{pH}$ value has always an important influence on the final products. In order to better understand the effect of the $\mathrm{pH}$ on the growth of $\mathrm{ZnO} \mathrm{NSs}$, the initial and the final $\mathrm{pH}$ values were carefully measured before and after the growth. Two sets of chemicals were used to vary the $\mathrm{pH}$ of the reactants, that is, procedures $\mathrm{A}$ and $\mathrm{B}$. The different initial $\mathrm{pH}\left(\mathrm{pH}_{\text {initial }}\right)$ values of the 


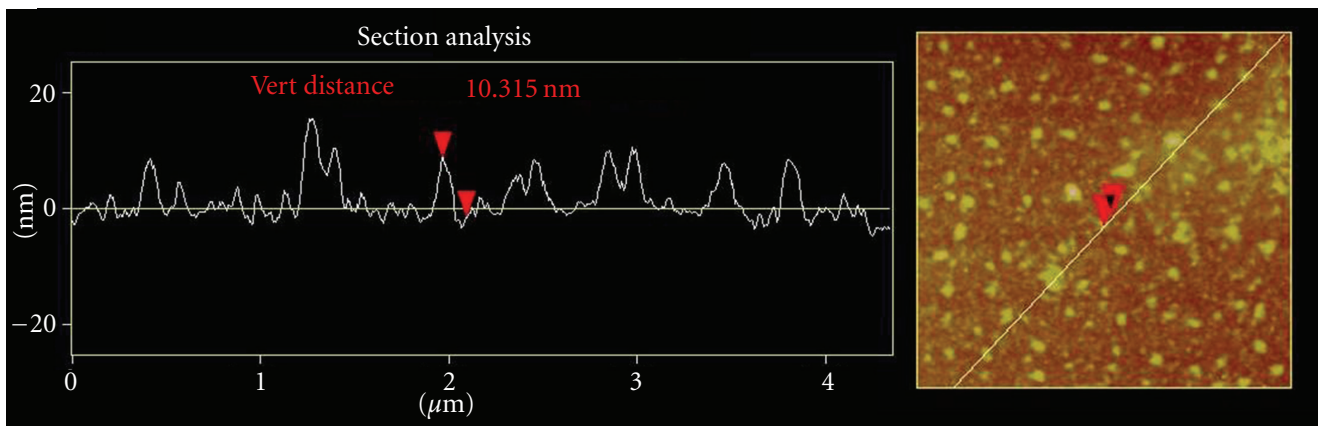

(a)

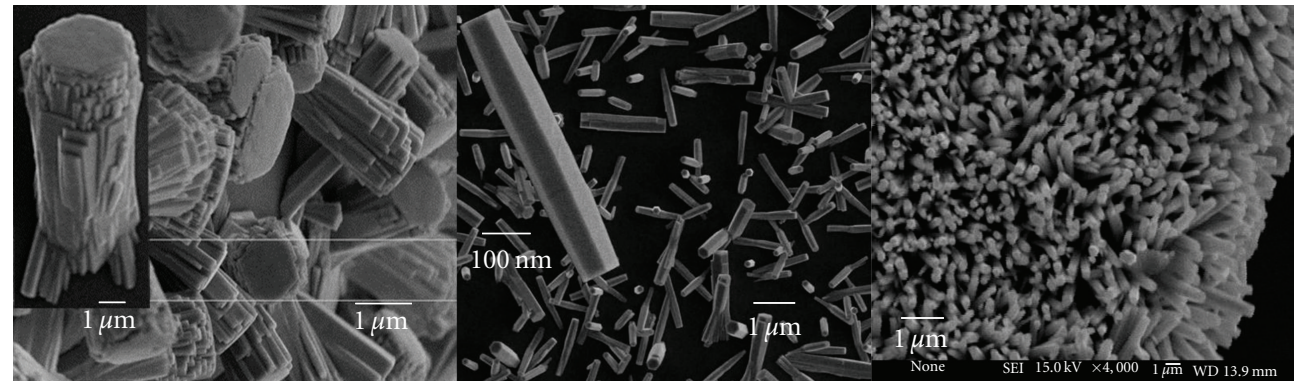

(b)

(c)

(d)

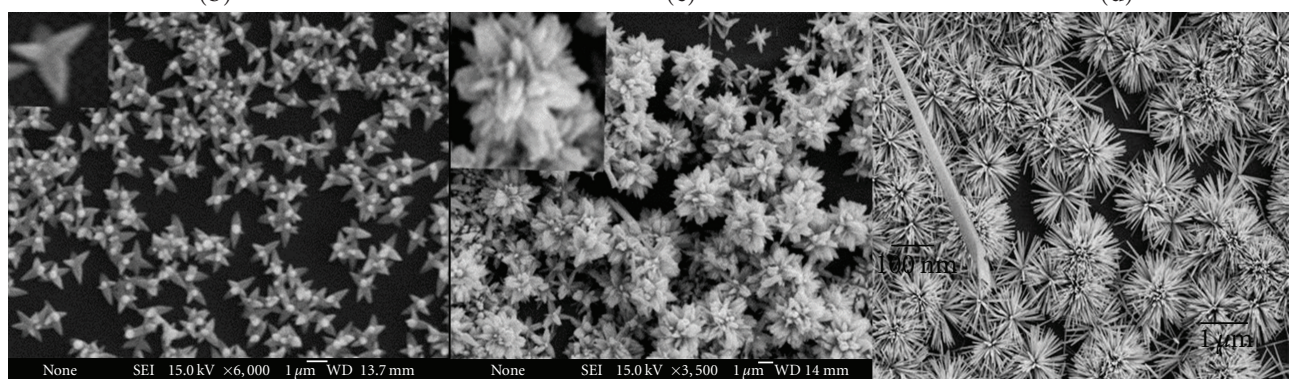

(e)

(f)

(g)

FIGURE 2: (a) shows the AFM image of the seed layer and the corresponding height profile. (b) SEM image of ZnO NSs on Si substrate grown with different aqueous solutions of $\mathrm{pH}$ value 1.8 ; (c) at $\mathrm{pH}$ value of 4.6 ; (d) at $\mathrm{pH}$ value of 6.6 ; (e) at $\mathrm{pH}$ value of 9.1; (f) at $\mathrm{pH}$ value of 10.8 ; $(\mathrm{g})$ at $\mathrm{pH}$ value of 11.2.The insets show enlarged SEM images of $\mathrm{ZnO}$ NSs (scale bar $=100 \mathrm{~nm}$ ).

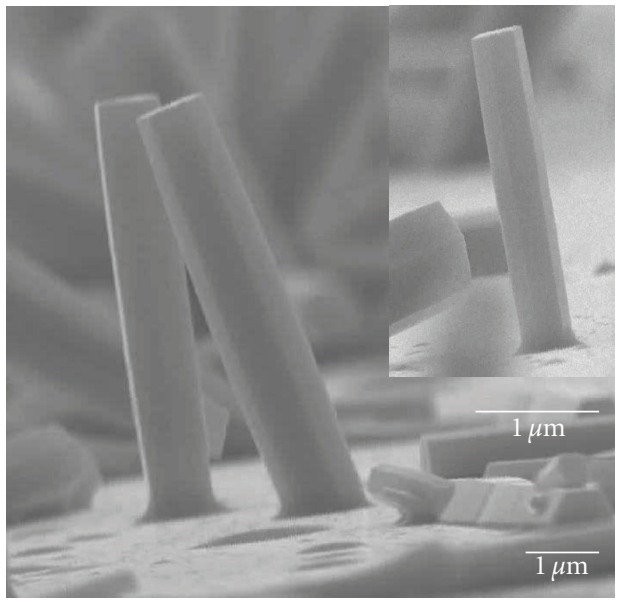

Figure 3: Cross-sectional SEM image of the $\mathrm{ZnO}$ NRs grown under conditions $T=90^{\circ} \mathrm{C}, t=6 \mathrm{hrs}, \mathrm{pH}=6.6$, and $C=100 \mathrm{mM}$. growth solution were adjusted to $1.8,2.5,3.5,4.6,6.6,8,9.2$, $10.7,11.2$, and 12.5, respectively. Figure 1 represents the plot of the $\mathrm{pH}_{\text {initial }}$ versus the final $\mathrm{pH}\left(\mathrm{pH}_{\text {final }}\right)$ recorded over a period of $5 \mathrm{hrs}$ using $100 \mathrm{mM}$ precursors concentration. The experiments carried out in this range of $\mathrm{pH}(1.8-12.5)$ either with procedure A or procedure B showed that the alkaline $\mathrm{pH}$ was relatively decreased with the same rate, while the acidic $\mathrm{pH}$ was converged to 5.4 apparently approaching the inherent value 6.6. It is to mention that the same experiments have been repeated four times giving the same results, indicating the reproducibility of this process. To correlate the growth rate of the $\mathrm{ZnO}$ NSs with the $\mathrm{pH}$, a set of samples were grown on the preseeded $\mathrm{Si}$ substrates with $T=90^{\circ} \mathrm{C}$ and $t=5 \mathrm{hrs}$ in adjusted $\mathrm{pH}_{\text {initial }}$ growth solutions. The inherent $\mathrm{pH}$ solution was transparent, and there were some visible white precipitates in the solution. The obtained NRs from the inherent $\mathrm{pH}$ solution have an average length of $2.2 \mu \mathrm{m}$ and diameter of $400 \mathrm{~nm}$. The length was measured 


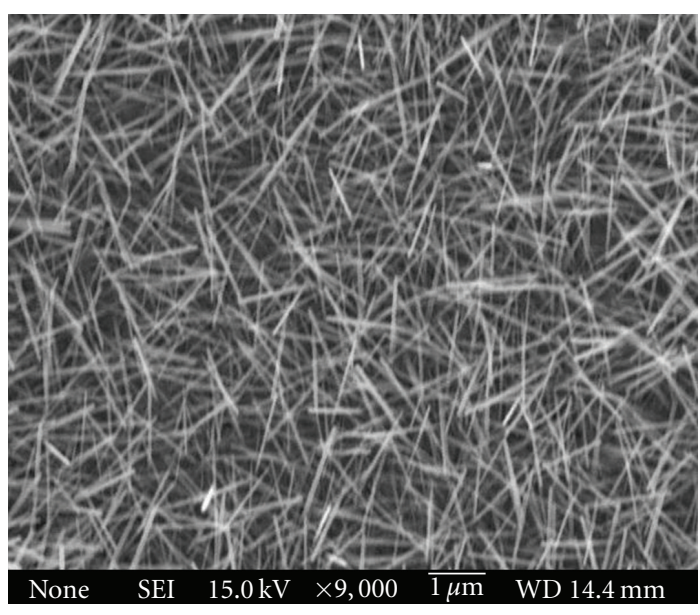

(a)

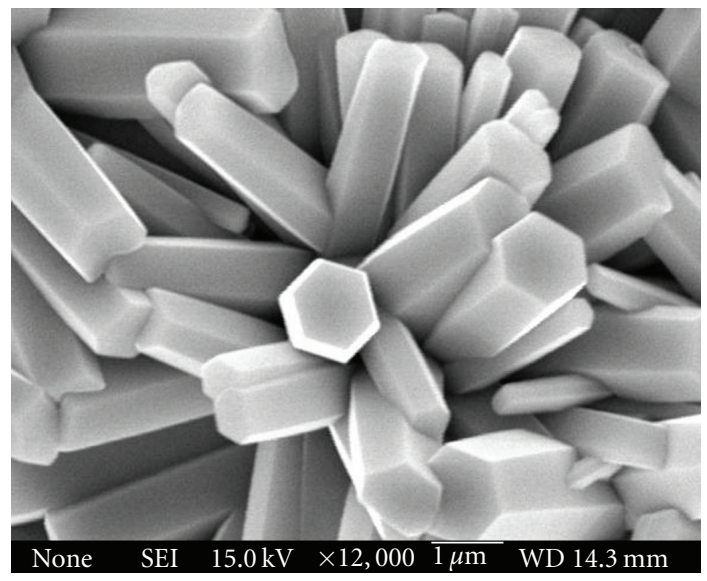

(c)

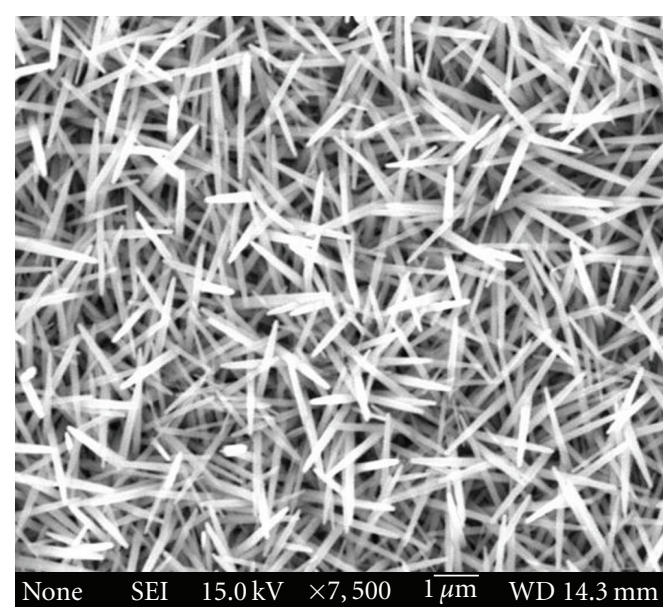

(b)

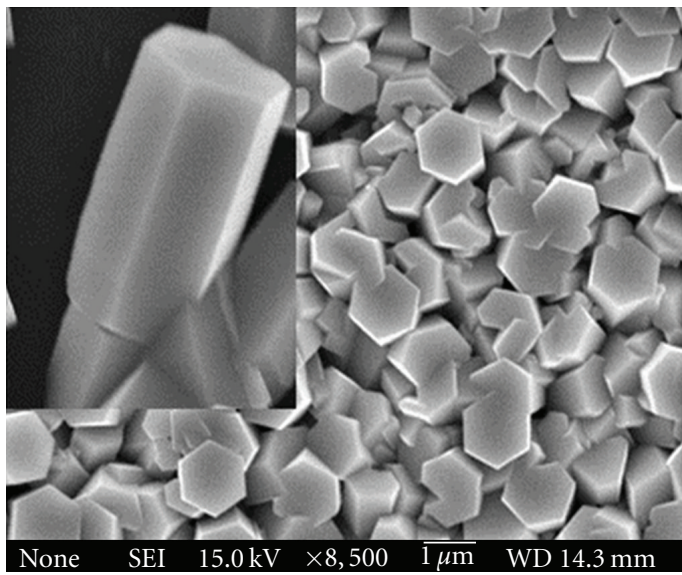

(d)

FIGURE 4: SEM images of ZnO NSs on Si substrate with different precursor concentrations of the growth aqueous solution (a) at $25 \mathrm{mM}$; (b) $50 \mathrm{mM}$; (c) $100 \mathrm{mM}$; (d) $300 \mathrm{mM}$. Inset shows the magnified view of the ZnO NSs (scale bar = $100 \mathrm{~nm}$ ).

from the cross-sectional SEM image (Figure 3) while the diameter was measured from the top view SEM as shown in Figure 2(d). Since in the inherent solution HMT was used as a precursor for the growth of $\mathrm{ZnO} \mathrm{NSs}$, first it hydrolyzes to produce the $\mathrm{OH}^{-}$and ammonia. Then, the $\mathrm{OH}^{-}$forms a complex with $\mathrm{Zn}^{2+}$, followed by thermal decomposition into $\mathrm{ZnO}$. The chemistry of the reaction during growth in the solution is discussed by Zainelabdin et al. [21]. When the $\mathrm{pH}$ was increased by adding $\mathrm{NH}_{3} \cdot \mathrm{H}_{2} \mathrm{O}$, the ammonia hydrolyzed into $\mathrm{NH}_{4}{ }^{+}$and hydroxide giving rise at the same way to the increases of $\mathrm{OH}^{-}$concentration in the solution. The following chemical reactions are governing the growth process:

$$
\begin{gathered}
\mathrm{NH}_{3} \cdot \mathrm{H}_{2} \mathrm{O} \longleftrightarrow \mathrm{NH}_{4}^{+}+\mathrm{OH}^{-} \\
\mathrm{Zn}^{2+}+2 \mathrm{OH}^{-} \longleftrightarrow \mathrm{Zn}(\mathrm{OH})_{2} \\
\mathrm{Zn}(\mathrm{OH})_{2} \longleftrightarrow \mathrm{ZnO}+\mathrm{H}_{2} \mathrm{O} \\
\mathrm{Zn}(\mathrm{OH})_{2}+\mathrm{OH}^{-} \longleftrightarrow\left[\mathrm{Zn}(\mathrm{OH})_{4}\right]^{2-}
\end{gathered}
$$

Figure 2 shows the SEM images of various NSs grown under different initial $\mathrm{pH}$ values. Figure 2(d) shows high density NRs structure prepared from solution at $\mathrm{pH}_{\text {initial }}=6.6$ without $\mathrm{NH}_{3} \cdot \mathrm{H}_{2} \mathrm{O}$, indicating that at this $\mathrm{OH}^{-}$ concentration only rod-like structures can be grown. When the $\mathrm{pH}$ was increased to 8 nanotetrapod ZnO NSs were obtained as shown in Figure 2(e); this can be attributed to the hydroxide concentration increase in the initial solution, giving rise to the anisotropic growth directions. When we increased the $\mathrm{pH}$ to 9.1 the growth rate increased due to the increases of $\mathrm{OH}^{-}$concentration which gives arise to $\mathrm{ZnO}$ particles in the solution. The resulting structure (Figure 2(f)) was a flower-like structure with thick arms. Figure $2(\mathrm{~g})$ shows $\mathrm{ZnO}$ urchin-like structures with needles length of $2 \mu \mathrm{m}$ and a diameter of $\sim 50 \mathrm{~nm}$ for samples prepared from a solution with $\mathrm{pH}=11.2$. The inset shows high magnification image of $\mathrm{ZnO}$ nanoneedle. Similar surface morphology structures were obtained at $\mathrm{pH}$ of 12.5 . We believe that by increasing the $\mathrm{OH}^{-}$ions as compared to $\mathrm{Zn}^{2+}$ concentrations reaction (4) immediately starts to take place. 


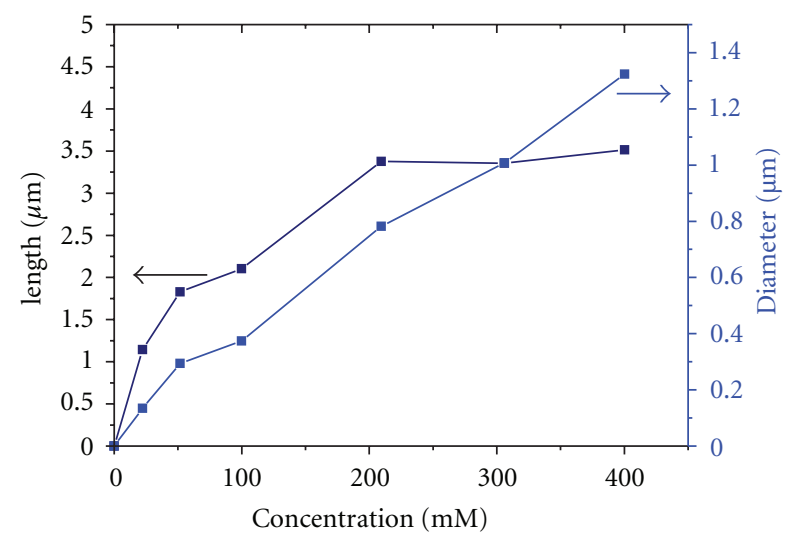

FIGURE 5: Plot of concentration versus average length and diameter of the $\mathrm{ZnO}$ NSs.

The $\left[\mathrm{Zn}(\mathrm{OH})_{4}\right]^{2-}$ acts as the new growth precursor while the nuclei obtained in reaction (3) serve as the seed. Therefore anisotropic growth of $\mathrm{ZnO}$ occurs at the active site of $\mathrm{ZnO}$ seed. Finally, we observed that for the high $\mathrm{pH}$ starting solution, the obtained structures were self-assembled.

By inspecting the cases for $\mathrm{pH}<7$ by adding either $\mathrm{HNO}_{3}$ or $\mathrm{HCl}$ very different results were obtained. Figures 2 (b) and 2(c) demonstrate the SEM images for the case with initial $\mathrm{pH}$ values of 1.8 and 4.6, respectively. The obtained structures were nanorods with hexagonal shape, the diameter and length were increased, and the density was largely decreased by the addition of $\mathrm{HNO}_{3}$ or $\mathrm{HCl}$ or by lowering the $\mathrm{pH}$ values. The dissolution of precipitates occurs according to reaction (2). As the $\mathrm{HNO}_{3}$ or $\mathrm{HCl}$ is added, more and more $\mathrm{Zn}^{2+}$ is formed and therefore the resulted $\mathrm{ZnO}$ nanorods grow to a larger length and diameter as shown in Figures 2 (b) and 2(c). However, very large dimension rods were obtained at $\mathrm{pH}<4.6$ and down to 1.8 in the $\mathrm{HNO}_{3}$ adjusted environment but they were eroded as clearly seen in the SEM image of Figure 2(a), and the etching was severe at the lowest $\mathrm{pH}$ values which also support the results that the $\mathrm{ZnO}$ starts to be etched in an acidic nature solution [22]. However, for $\mathrm{pH}<4.6$ no growth was obtained when the $\mathrm{pH}$ value was lowered by $\mathrm{HCl}$. This can be due to the fact that the etching was dominating over the growth. It is also worthwhile to mention that after inspecting the SEM images of these samples there were no signs of a seed layer ( $\mathrm{ZnO}$ nanoparticles) and the substrate was clean which shows that the etching was dominant.

3.2. Effect of the Precursor Concentration. In this section the concentration variation of the reactants using inherent $\mathrm{pH}$ value of 6.6 is discussed. It is well known that increasing or decreasing the concentration of the chemical reactants will eventually influence the resultant products. In the original paper which describes the growth of $\mathrm{ZnO}$ NRs via aqueous solutions, they have obtained microrods since a high concentration of the initial reactants was used [23]; when a relatively low concentration was used by the same authors the ZnO NRs were achieved [24]. This implies that a good control over the chemical reactants can be utilized to gain direct control over the dimensions of the final $\mathrm{ZnO}$ NRs. According to this fact we have studied the effect of the reactants concentration on the dimensions of NRs as mentioned above starting by the inherent $\mathrm{pH}$ value. Scanning electron microscope images of $\mathrm{ZnO}$ NRs grown at different concentrations of the aqueous solution containing equimolar concentrations of $\mathrm{Zn}\left(\mathrm{NO}_{3}\right)_{2} \cdot 6 \mathrm{H}_{2} \mathrm{O}$ and HMT are shown in Figure 4; inset shows the magnified SEM image. The density, length, and diameter of the $\mathrm{ZnO}$ nano-/microrods are varied with the concentration applied during the synthesis; a higher concentration yields a micro-sized diameter with densely packed c-axis aligned $\mathrm{ZnO}$ rods as shown in Figure 4(d). Furthermore, for concentrations $>400 \mathrm{mM}$ the microrod sized $\mathrm{ZnO}$ is converted into a polycrystalline thin film. On the other hand a low concentration (10 to $25 \mathrm{mM}$ ) of aqueous solution results in wire-like NRs with a diameter $<100 \mathrm{~nm}$, and the length was found to be $1.2 \mu \mathrm{m}$, evenly covering the substrate as revealed in Figures 4(a) and 4(b). Moreover, for concentrations less than $5 \mathrm{mM}$ no growth was achieved on the substrate at the specified duration of $5 \mathrm{hrs}$, instead only residual $\mathrm{ZnO}$ was deposited on the bottom of the glass beaker suggesting that the longer time is required to grow $\mathrm{ZnO} \mathrm{NSs}$. When the growth was established for longer time (20 hrs) ultrathin NWs were achieved covering the substrate evenly. Nevertheless, Zhu et al. have synthesized $\mathrm{ZnO}$-based core/shell structure at $5 \mathrm{mM}$ at shorter time by modifying the aqueous solution [25]. The results of the precursor concentration variation with the $\mathrm{ZnO}$ NRs dimension are summarized in Figure 5. The graph clearly demonstrates that a linear relation can be drawn between the increase of the concentration and the NRs dimensions; interestingly the diameter of the NRs increases gradually, while the length becomes constant above $200 \mathrm{mM}$. This implies that there is a critical length for the $\mathrm{ZnO}$ NRs at which further increase of the concentration will not have any role in the axial growth direction whereas the radial direction grows continuously and at high enough concentration the rods merge to form continuous thin film.

3.3. Influence of the Growth Time. To investigate influence of the growth time on the $\mathrm{ZnO} \mathrm{NRs}$, we have grown the $\mathrm{ZnO} \mathrm{NRs}$ in equimolar concentration $(100 \mathrm{mM})$ of HMT and $\mathrm{Zn}\left(\mathrm{NO}_{3}\right)_{2} \cdot 6 \mathrm{H}_{2} \mathrm{O}$ at constant temperature of $90^{\circ} \mathrm{C}$ and inherent $\mathrm{pH}$ value of 6.6 for 1, 3, 6, 10, and 20 hrs. Figure 6 shows the cross-sectional SEM images of the $\mathrm{ZnO}$ NRs grown at different durations. It can be noticed from the figure that the growth duration is an important factor to control the size of the final $\mathrm{ZnO}$ structure. Figure 6(a) shows SEM image of ZnO NRs grown for a time of $1 \mathrm{hr}$, with an average length of $500 \mathrm{~nm}$, indicating that rods are emerging on the nucleation sites. These embryonic NRs continue to grow with increasing the growth duration. When growth was conducted for 3 hrs average sized NRs with length of $1.0 \mu \mathrm{m}$ were obtained (Figure 6(b)). By further increasing the growth time to $6 \mathrm{hrs}$ the NRs length was boosted to $1.8 \mu \mathrm{m}$ as revealed in Figure 6(c). The length has increased up to $2.2 \mu \mathrm{m}$ when the growth time was increased to $10 \mathrm{hrs}$ as seen in Figure 6(d), while no further increase of the $\mathrm{ZnO}$ NRs size was observed above 10 hrs. The inset in Figure 6 shows a top 

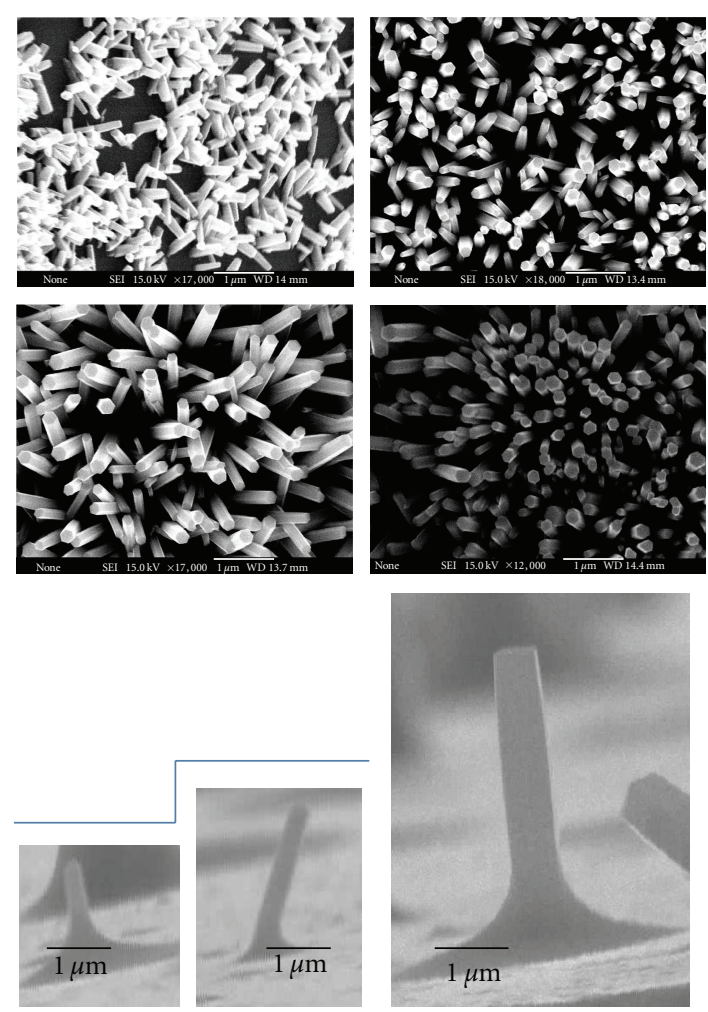

(a)

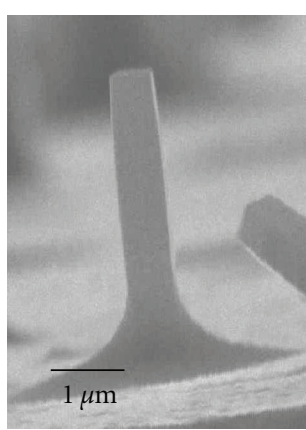

(b)

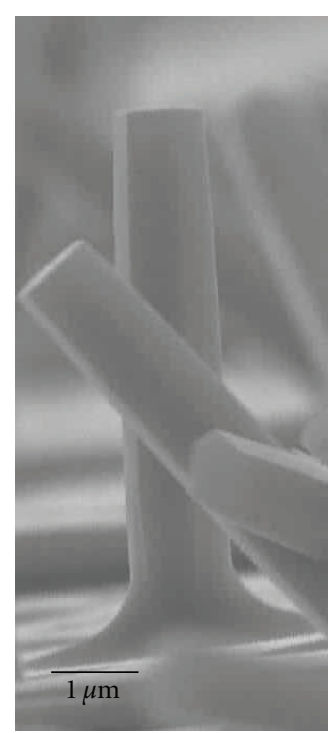

(c)

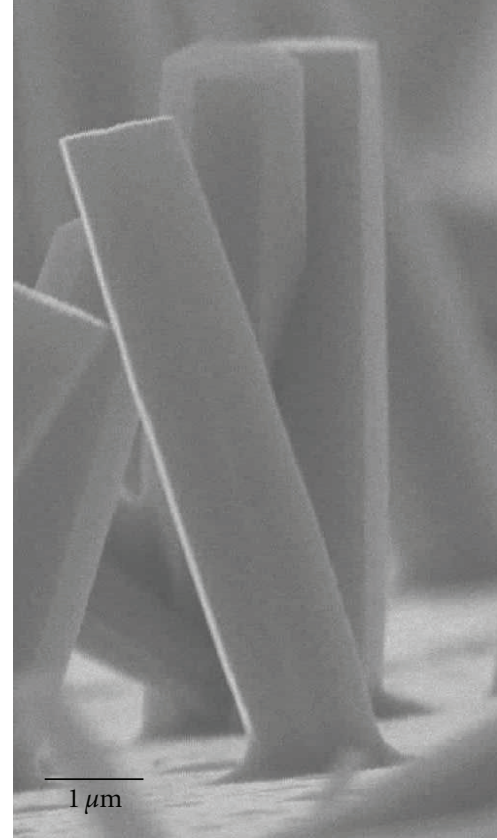

(d)

Figure 6: Cross-sectional SEM images of ZnO NRs on Si substrate at different growth times: (a) $1 \mathrm{hr}$; (b) $3 \mathrm{hrs;} \mathrm{(c)} 6 \mathrm{hrs}$; (d) $10 \mathrm{hrs}$ at $T$ = $90^{\circ} \mathrm{C}$. The inset shows the corresponding top view of the SEM images.

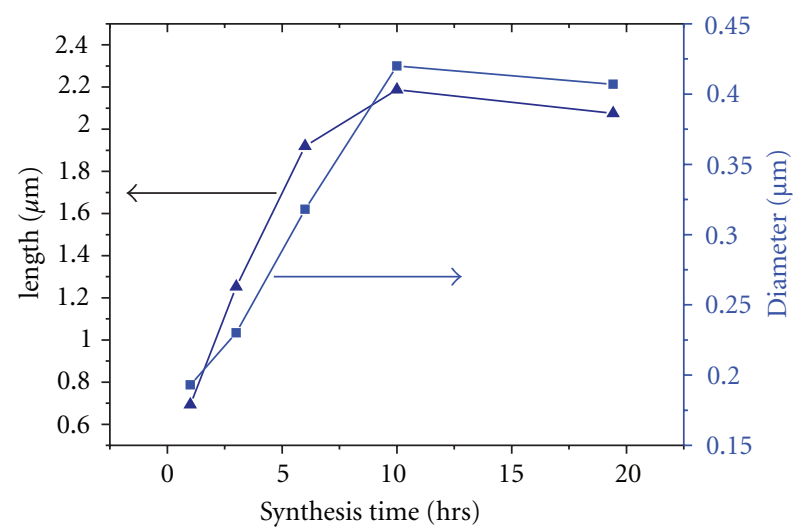

Figure 7: Plot of ZnO NRs synthesis time versus change in average length and diameter.

view of the corresponding SEM images to the ones shown in the figure; here the diameter of the obtained $\mathrm{ZnO}$ NRs was changed from $150 \mathrm{~nm}$ to $500 \mathrm{~nm}$ with the change of time as stated above. Utilizing the cross-sectional and top view SEM images we calculated the lengths and diameters of $\mathrm{ZnO}$ NRs with growth time, and the result is summarized in Figure 7. The results indicated that continuous and steady growth of $\mathrm{ZnO}$ nanostructures precedes until the first $10 \mathrm{hrs}$ and then the system would be in closure-precipitation equilibrium stage as indicated in Figure 7. It is believed that with the passage of time the $\mathrm{OH}^{-}$would continuously hydrolyze in the water solution from HMT up to $10 \mathrm{hrs}$ then the $\mathrm{OH}^{-}$ would be consumed. The results show that the density of the $\mathrm{ZnO}$ nanostructures depends on the reaction time. The threshold time for growing $\mathrm{ZnO}$ NRs was observed to be one hour; therefore no growth was obtained below one hour.

3.4. Influence of the Growth Temperature. The effect of $T$ on the $\mathrm{ZnO}$ NSs was also investigated. In our experiments, a set of samples were grown in the aqueous solution using a $\mathrm{pH}$ $=6.6, t=5 \mathrm{hrs}$, and $100 \mathrm{mM}$ precursors concentration in a controlled digital laboratory oven. Our growth temperature was changed from $50^{\circ} \mathrm{C}$ up to $110^{\circ} \mathrm{C}$. The SEM images of this set of samples are shown in Figure 8. Figure 9 shows the plot of the aspect ratio of $\mathrm{ZnO}$ NRs versus $T$ when the growth was performed in aqueous solution with an initial $\mathrm{pH}$ of 6.6. From these figures it can be seen that by changing $T$ the aspect ratio is gradually increased up to $95^{\circ} \mathrm{C}$. However, no further increase in the aspect ratio was observed at $110^{\circ} \mathrm{C}$. The structure remained rodlike and the density was almost the same. Therefore, we believe that the size of the $\mathrm{ZnO}$ NSs can be controlled by changing $T$, and we suggest that the feasible $T$ for the growth is $<100^{\circ} \mathrm{C}$ since it is an aqueous based (water-based) solution. The crystallinity of the $\mathrm{ZnO}$ NRs grown at $90^{\circ} \mathrm{C}$ for $5 \mathrm{hrs}$ and with a $\mathrm{pH} 6.6$ 


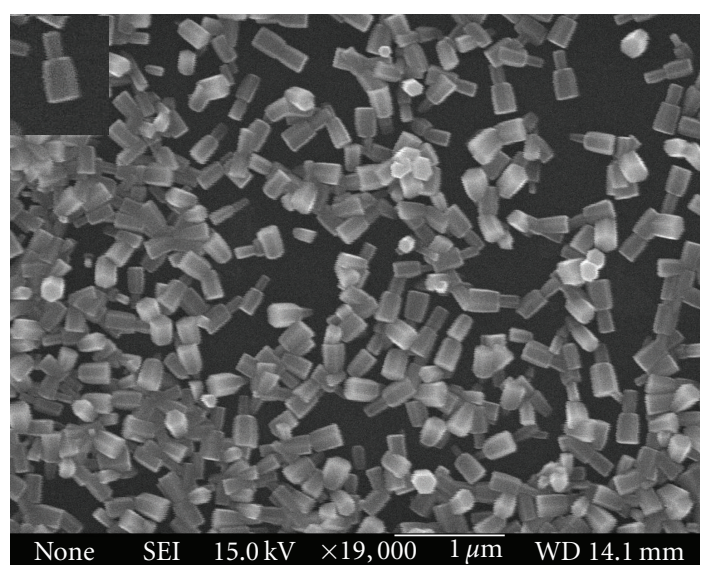

(a)

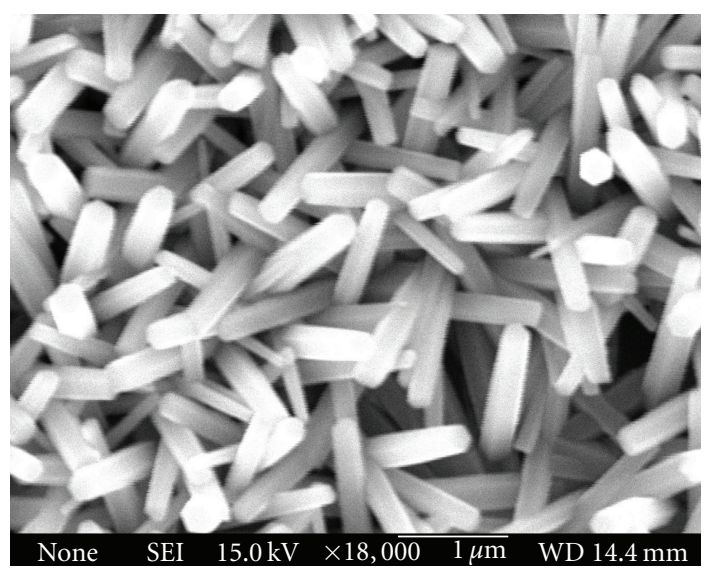

(c)

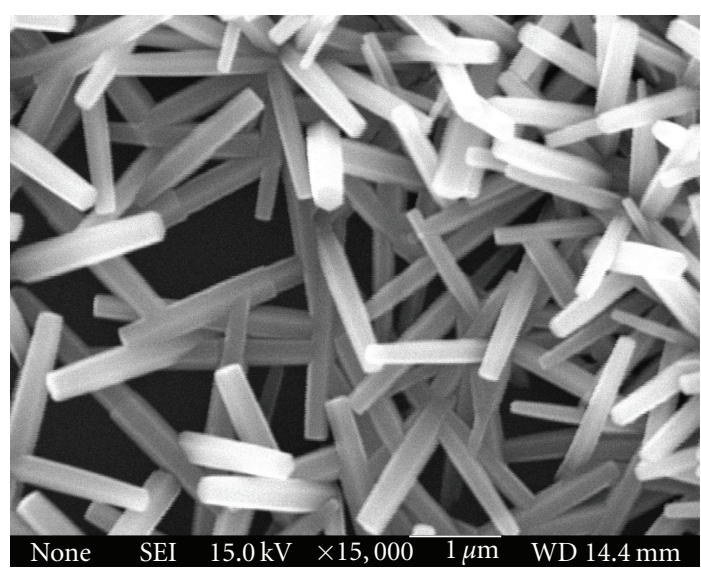

(b)

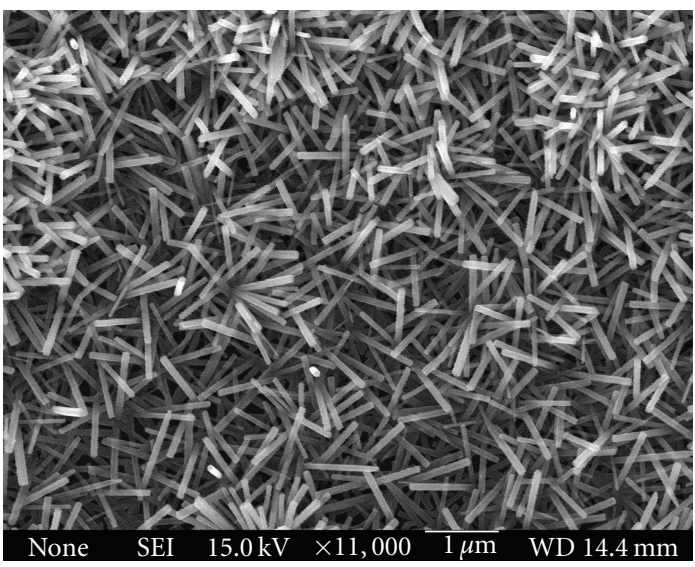

(d)

Figure 8: SEM images of ZnO NSs on Si substrates for the growth temperatures (a) $50^{\circ} \mathrm{C}$; (b) $70^{\circ} \mathrm{C}$; (c) $90^{\circ} \mathrm{C}$; (d) $110^{\circ} \mathrm{C}$ for $5 \mathrm{hrs}$ and at $100 \mathrm{mM}$ concentration. The inset is the magnified image (scale $100 \mathrm{~nm}$ ) of single rod.

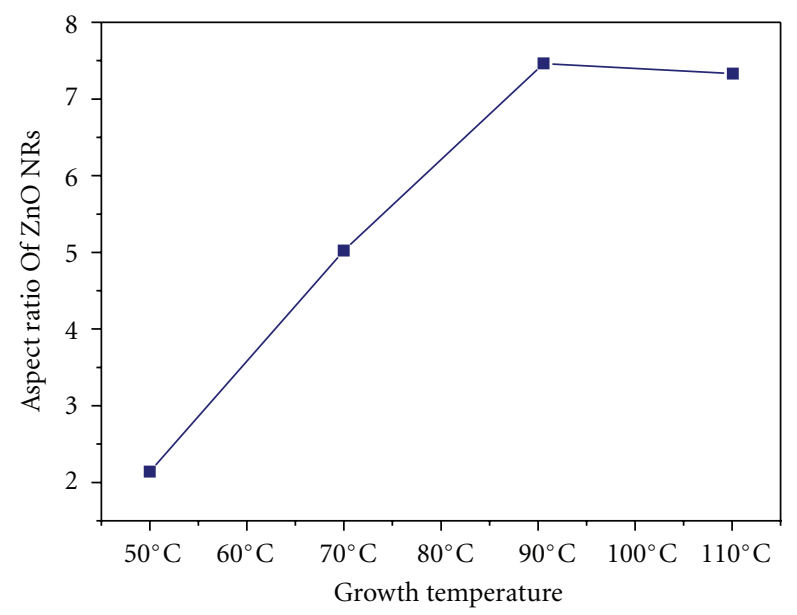

FIGURE 9: Plot of aspect ratio of ZnO NRs versus growth temperature $(T)$ under the conditions of $C=100 \mathrm{mM}, t=5 \mathrm{hrs}$, and inherent $\mathrm{pH}$.

was investigated by XRD as shown in Figure 10. The XRD pattern exhibited sharp diffraction peaks which correspond to $\mathrm{ZnO}$ wurtzite structure and agree well with the values available in the JCPDS 36-1451. From the above discussion we can say that the $\mathrm{pH}$ controls the morphology and the precursor concentration controls the nucleation density, while the growth time controls the aspect ratio and finally the temperature control the aspect ratio and morphology. By 


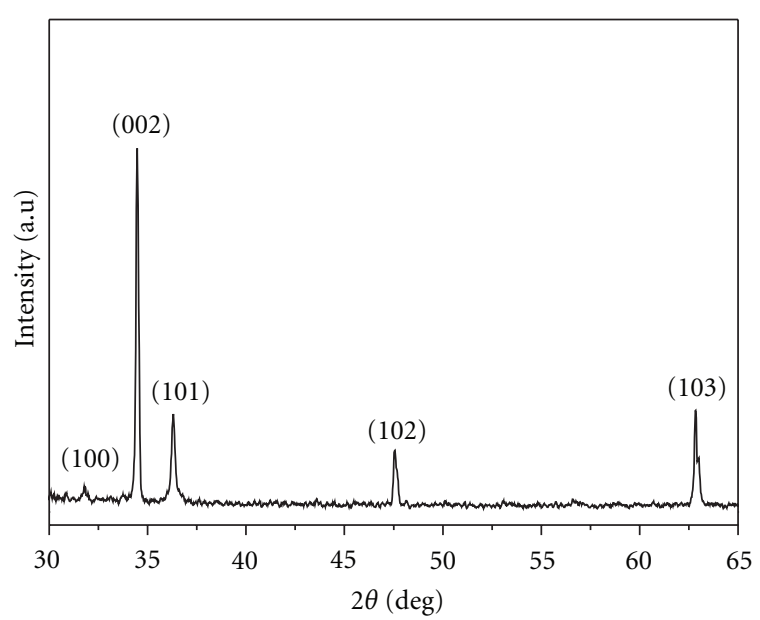

FIGURE 10: XRD pattern of ZnO NSs grown under the conditions of $T=90^{\circ} \mathrm{C}, t=5 \mathrm{hrs}$, and inherent $\mathrm{pH}$.

adjusting these parameters, we can control the growth and obtain the desired $\mathrm{ZnO}$ NSs.

\section{Conclusion}

In conclusion, we studied the morphological control of $\mathrm{ZnO}$ nanostructures by adjusting possible parameters such as the $\mathrm{pH}$, the concentration, the time, and the growth temperature. We have observed that the initial $\mathrm{pH}$ employed always changes during the growth, tending toward a neutral $\mathrm{pH}$. Nanotetrapod-like, flower-like, and urchin-like $\mathrm{ZnO}$ nanostructures were obtained at higher $\mathrm{pH}$ values $(\geq 8)$, while rod-like structures were obtained at lower $\mathrm{pH}$. It was also noticed that the $\mathrm{ZnO}$ NRs were etched at a $\mathrm{pH} \leq$ 4.6. Furthermore, the precursor concentration, time, and temperature of growth were found to affect the morphology and dimensions of the $\mathrm{ZnO}$ nanostructures, changing from nanowires to nanorods and even to a film-like structure. We believe that the morphological and structural characteristics of the grown samples can be controlled by simply tuning the above-mentioned growth parameters to obtain the desired nanostructures as these experiments were reproducible.

\section{Acknowledgment}

The authors acknowledge the partial financial support from the advanced Functional Material project Sweden.

\section{References}

[1] Ü. Özgür, Y. I. Alivov, C. Liu et al., "A comprehensive review of $\mathrm{ZnO}$ materials and devices," Journal of Applied Physics, vol. 98, no. 4, Article ID 041301, pp. 1-103, 2005.

[2] C. F. Klingshirn, "ZnO: material, physics and applications," ChemPhysChem, vol. 8, no. 6, pp. 782-803, 2007.

[3] W. J. E. Beek, M. M. Wienk, and R. A. J. Janssen, "Hybrid solar cells from regioregular polythiophene and $\mathrm{ZnO}$ nanoparticles," Advanced Functional Materials, vol. 16, no. 8, pp. 1112 1116, 2006.
[4] A. J. Gimenez, J. M. Yáñez-Limón, and J. M. Seminario, “ZnOpaper based photoconductive UV sensor," Journal of Physical Chemistry C, vol. 115, no. 1, pp. 282-287, 2011.

[5] Y. Wei, Y. Li, X. Liu, Y. Xian, G. Shi, and L. Jin, "ZnO nanorods/Au hybrid nanocomposites for glucose biosensor," Biosensors and Bioelectronics, vol. 26, no. 1, pp. 275-278, 2010.

[6] X. M. Zhang, M. Y. Lu, Y. Zhang, L. J. Chen, and Z. L. Wang, "Fabrication of a high-brightness blue-light-emitting diode using a ZnO-Nanowire array grown on p-GaN thin film," Advanced Materials, vol. 21, no. 27, pp. 2767-2770, 2009.

[7] M. Willander, O. Nur, Q. X. Zhao et al., "Zinc oxide nanorod based photonic devices: recent progress in growth, lightemitting diodes and lasers," Nanotechnology, vol. 20, no. 33, Article ID 332001, 2009.

[8] H. J. Bolink, E. Coronado, D. Repetto, and M. Sessolo, "Air stable hybrid organic-inorganic light emitting diodes using $\mathrm{ZnO}$ as the cathode," Applied Physics Letters, vol. 91, no. 22, Article ID 223501, 2007.

[9] S. Nicolay, S. Fay, and C. Ballif, "Growth Model of MOCVD Polycrystalline ZnO," Crystal Growth and Design, vol. 9, no. 11, pp. 4957-4962, 2009.

[10] H. Zeng, J. Cui, B. Cao, U. Gibson, Y. Bando, and D. Golberg, "Electrochemical deposition of $\mathrm{ZnO}$ nanowire arrays: oganization, doping, and properties," Science of Advanced Materials, vol. 2, no. 3, pp. 336-358, 2010.

[11] Y. Sato, K. Yanagisawa, N. Oka, S. I. Nakamura, and Y. Shigesato, "Sputter deposition of Al-doped $\mathrm{ZnO}$ films with various incident angles," Journal of Vacuum Science and Technology A, vol. 27, no. 5, pp. 1166-1171, 2009.

[12] J. P. Mosnier, R. J. O’Haire, E. McGlynn et al., “ZnO films grown by pulsed-laser deposition on soda lime glass substrates for the ultraviolet inactivation of Staphylococcus epidermidis biofilms," Science and Technology of Advanced Materials, vol. 10, no. 4, Article ID 045003, 2009.

[13] X. Y. Chen, A. M. C. Ng, F. Fang et al., "The influence of the $\mathrm{ZnO}$ seed layer on the ZnO Nanorod/GaN LEDs," Journal of the Electrochemical Society, vol. 157, no. 3, pp. H308-H311, 2010.

[14] J. Song and S. Lim, "Effect of seed layer on the growth of $\mathrm{ZnO}$ nanorods," Journal of Physical Chemistry C, vol. 111, no. 2, pp. 596-600, 2007.

[15] D. Vernardou, G. Kenanakis, S. Couris, E. Koudoumas, E. Kymakis, and N. Katsarakis, "pH effect on the morphology of $\mathrm{ZnO}$ nanostructures grown with aqueous chemical growth," Thin Solid Films, vol. 515, no. 24, pp. 8764-8767, 2007.

[16] S. D. G. Ram, M. A. Kulandainathan, and G. Ravi, "On the study of $\mathrm{pH}$ effects in the microwave enhanced rapid synthesis of nano-ZnO," Applied Physics A, vol. 99, no. 1, pp. 197-203, 2010.

[17] H. Zhang, J. Feng, J. Wang, and M. Zhang, "Preparation of $\mathrm{ZnO}$ nanorods through wet chemical method," Materials Letters, vol. 61, no. 30, pp. 5202-5205, 2007.

[18] Z. Zhang, M. Lu, H. Xu, and W. S. Chin, "Shape-controlled synthesis of zinc oxide: a simple method for the preparation of metal oxide nanocrystals in non-aqueous medium," Chemistry-A, vol. 13, no. 2, pp. 632-638, 2007.

[19] J. Yahiro and H. Imai, "Morphological design of zinc oxide films grown in aqueous solutions," Key Engineering Materials, vol. 320, pp. 155-158, 2006.

[20] L. E. Greene, M. Law, D. H. Tan et al., "General route to vertical $\mathrm{ZnO}$ nanowire arrays using textured $\mathrm{ZnO}$ seeds," Nano Letters, vol. 5, no. 7, pp. 1231-1236, 2005.

[21] A. Zainelabdin, S. Zaman, G. Amin, O. Nur, and M. Willander, "Deposition of well-aligned $\mathrm{ZnO}$ nanorods at $50^{\circ} \mathrm{C}$ on metal, 
semiconducting polymer, and copper oxides substrates and their structural and optical properties," Crystal Growth and Design, vol. 10, no. 7, pp. 3250-3256, 2010.

[22] J. Zhou, N. Xu, and Z. L. Wang, "Dissolving behavior and stability of $\mathrm{ZnO}$ wires in biofluids: a study on biodegradability and biocompatibility of $\mathrm{ZnO}$ nanostructures," Advanced Materials, vol. 18, no. 18, pp. 2432-2435, 2006.

[23] L. Vayssieres, K. Keis, S. E. Lindquist, and A. Hagfeldt, "Purpose-built anisotropie metal oxide material: 3D highly oriented microrod array of ZnO," Journal of Physical Chemistry $B$, vol. 105, no. 17, pp. 3350-3352, 2001.

[24] L. Vayssieres, "Growth of arrayed nanorods and nanowires of $\mathrm{ZnO}$ from aqueous solutions," Advanced Materials, vol. 15, no. 5, pp. 464-466, 2003.

[25] Y. F. Zhu, D. H. Fan, and W. Z. Shen, "A general chemical conversion route to synthesize various $\mathrm{ZnO}$-based core/shell structures," Journal of Physical Chemistry C, vol. 112, no. 28, pp. 10402-10406, 2008. 

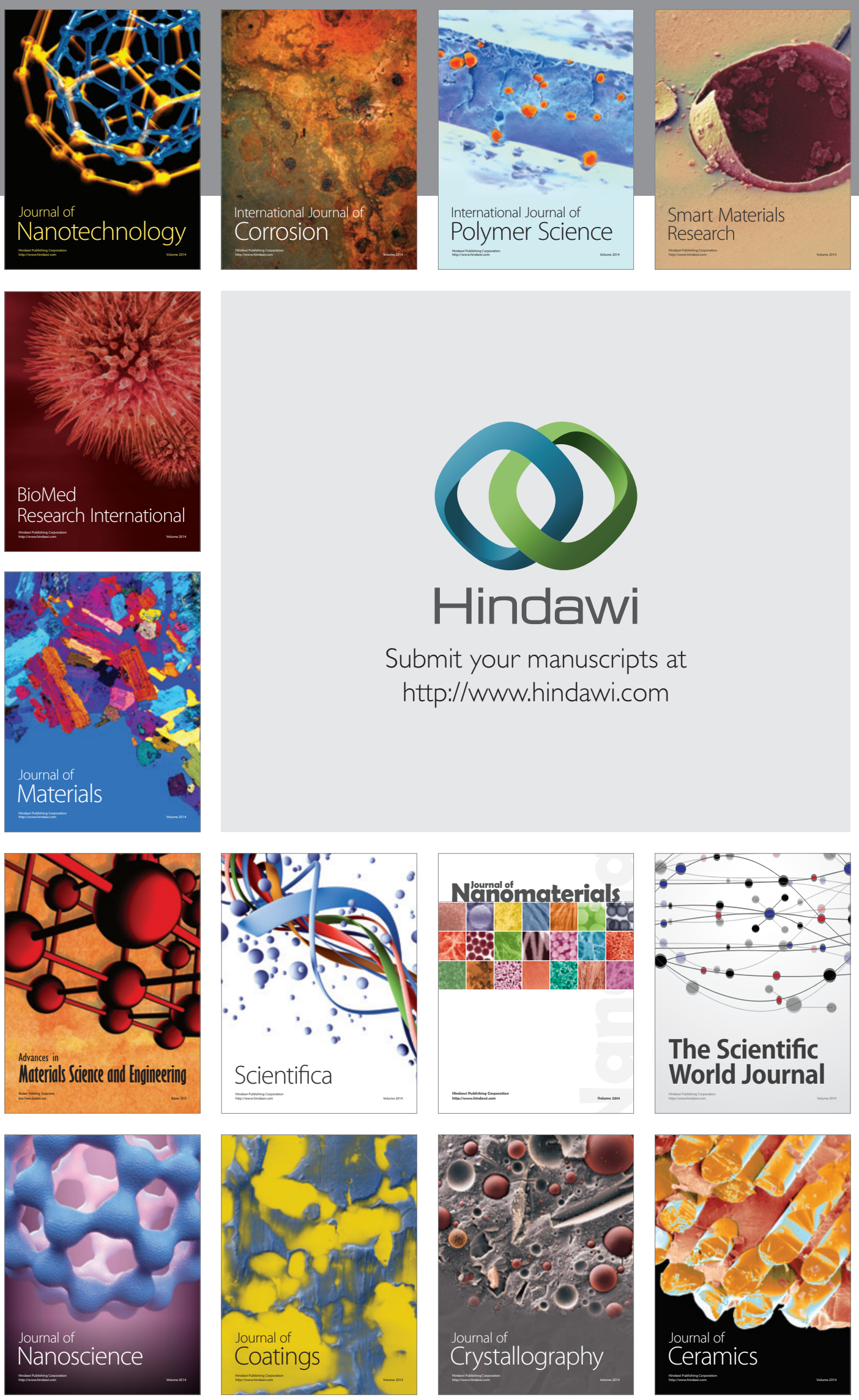

The Scientific World Journal

Submit your manuscripts at

http://www.hindawi.com

\section{World Journal}

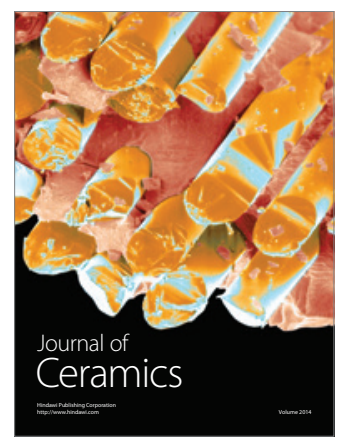

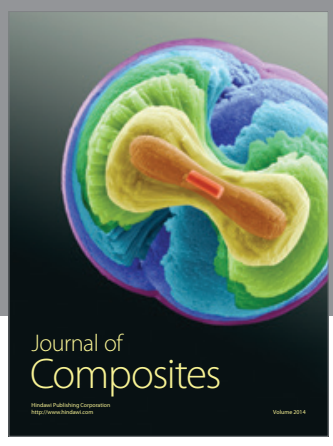
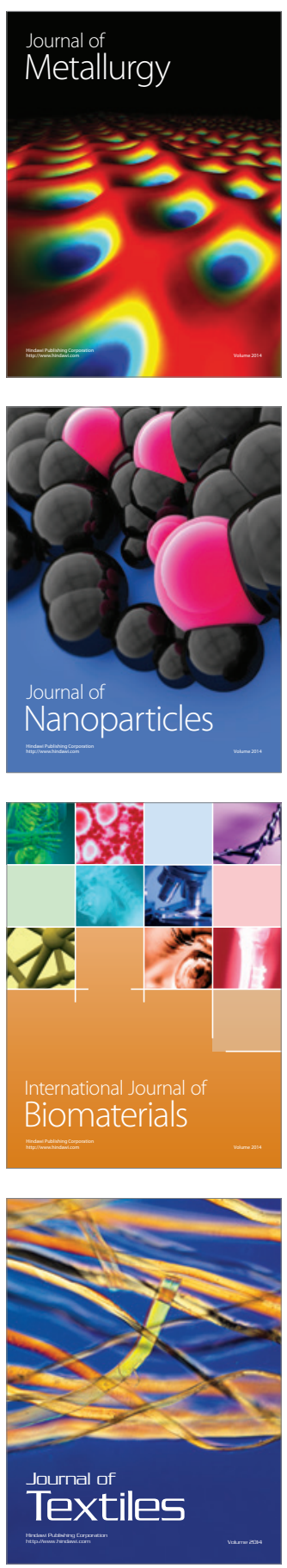